\title{
A TEM INVESTIGATION ON PRECIPITATION BEHAVIOR OF AEREX350 SUPERALLOY
}

\author{
Mojtaba Samiee, Sirous Asgari \\ Department of Materials Science and Engineering, Sharif University of Technology
} Tehran, IRAN

Keywords: AEREX ${ }^{\mathrm{TM}} 350$, Precipitation Behavior, Solution Treatment.

\begin{abstract}
The influence of solution treatment on precipitation behavior of AEREX $^{\mathrm{TM}_{3}} 30$ was investigated using hardness testing, TEM and SEM. Samples were solution treated at $1050^{\circ} \mathrm{C}$ and $1075^{\circ} \mathrm{C}$ for 1 hr and then aged at $700{ }^{\circ} \mathrm{C}, 750{ }^{\circ} \mathrm{C}$ and $800{ }^{\circ} \mathrm{C}$ for $1,2,4,8$ and 25 hrs. It was found that different solution treatment may be used for different applications of $\mathrm{AEREX}^{\mathrm{TM}} 350$.
\end{abstract}

\section{Introduction}

$\mathrm{AEREX}^{\mathrm{TM}} 350$ is a wrought $\mathrm{Ni}-\mathrm{Co}$ base superalloy which was first developed as a fastener alloy and is a member of MULTIPHASE (MP) family of alloys which are thermo-mechanically processed and are used in structurally and physically demanding applications including aerospace and petrochemical industries. MP35N, the original member of the MP family, is commercially strengthened by cold working [1, 2]. Due to chemical composition of $\mathrm{AEREX}^{\mathrm{TM}} 350$, the alloy benefits from precipitation hardening and solid solution strengthening as well as cold working and can be used in higher temperatures [3].

Previous investigations on precipitation behavior of AEREX $^{\mathrm{TM}_{350}}$ have shown that the major phases in the alloy are $\gamma^{\prime}\left(\mathrm{Ni}_{3} \mathrm{AlTi}\right)$ with $\mathrm{L}_{2}$ structure and $\eta\left(\mathrm{Ni}_{3} \mathrm{Ti}\right)$ with $\mathrm{D0}_{24}$ structure [3-5]. Studies indicate that the $\gamma^{\prime}$ phase is the major strengthening phase $[3,4]$. Due to the very low carbon content of the alloy, carbides do not play an important role in strengthening. $\eta$ phase appears at grain boundaries and in the grain interiors during high temperature aging and is generally plate shaped and nucleates along the (111) crystallographic planes of the matrix. S. Asgari has shown that the overaging increases the volume fraction of $\eta$ [4]. It has been reported that $\eta$ phase may enhance or deteriorates the mechanical properties of superalloys depending on its morphology [6]. It has also been shown that cold work prior to aging increases the volume fraction of $\eta$ phase [7]. The goal of this study is to investigate the microstructure evolution during the precipitation behavior of $\mathrm{AEREX}^{\mathrm{TM}} 350$.

\section{Experimental Procedure}

The alloy was supplied by SPS Technologies, Jenkintown PA, as hot rolled bars of AEREX ${ }^{\mathrm{TM}} 350(45 \% \mathrm{Ni}, 25 \% \mathrm{Co}, 17 \% \mathrm{Cr}, 4 \%$ $\mathrm{Ta}, 3 \% \mathrm{Mo}, 2 \% \mathrm{Ti}$, and $1 \% \mathrm{Al}$ ). Samples were cut from the as received material. Solution treatments were done at $1050^{\circ} \mathrm{C}$ and $1075^{\circ} \mathrm{C}$ for one hour in argon atmosphere and subsequently water quenched. Solution treatment temperatures were selected according to $\eta$ solvus temperature based on earlier work [4]. The solution treated samples were then aged at 700,750 and $800^{\circ} \mathrm{C}$ for $1,2,4,8$ and 25 hours in air and cooled to room temperature in air. Hardness tests were used to investigate the precipitation behavior. The samples were ground and polished before hardness testing and at least three indentations were made for each hardness measurement and the average is reported. For TEM studies, slices of about $0.4 \mathrm{~mm}$ in thickness were cut using an electric-discharge machine (EDM), and were subsequently ground to a thickness of $0.1 \mathrm{~mm}$. Discs of $3 \mathrm{~mm}$ in diameter were cut from the thinned wafers and TEM foils were prepared by electropolishing these discs in a Struers Tenupol 5 jet-polishing unit using a solution of $50 \mathrm{ml} \mathrm{H} 2 \mathrm{SO} 4,15 \mathrm{ml} \mathrm{HNO} 3$ and $220 \mathrm{ml}$ methanol and a voltage of 12 volts at $6^{\circ} \mathrm{C}$. A Philips CM200 TEM/STEM operating at 200 $\mathrm{kV}$ was used for transmission electron microscopy studies.

\section{Results and Discussion}

Tables I and $\Pi$ show the hardness results of solution treated and aged samples. Figures 1 and 2 show the hardness curves for the samples solution treated at $1050^{\circ} \mathrm{C}$ and $1075^{\circ} \mathrm{C}$, respectively. At all aging times, the hardness of samples solution treated at $1050^{\circ} \mathrm{C}$ is generally higher than the samples solution treated at $1075^{\circ} \mathrm{C}$. The sharp increase in hardness of samples solution treated at $1050^{\circ} \mathrm{C}$ for short aging times is followed by a steady but small increase in hardness for aging times longer than $4 \mathrm{~h}$. The hardness of samples solution treated at $1075^{\circ} \mathrm{C}$ increases steadily with increasing aging times.

Figures 3 and 4 show microstructures of samples solution treated at $1050^{\circ} \mathrm{C}$ and $1075^{\circ} \mathrm{C}$ respectively. Since $1050^{\circ} \mathrm{C}$ is below the $\eta$ solvus temperature, microstructure of the samples solution treated at $1050^{\circ} \mathrm{C}$ consists of $\eta$ phase while these precipitates were not found in samples solution treated at 1075 ${ }^{\circ} \mathrm{C}$. The $\eta$ precipitates have formed at grain boundaries.

Figure 5 shows a bright-field image of a sample solution treated at $1050^{\circ} \mathrm{C}$ for $1 \mathrm{hr}$ and aged at $800^{\circ} \mathrm{C}$ for $25 \mathrm{hrs}$. Grain boundary $\eta$ precipitates formed during solution treatment are clearly seen as parallel blocks aligned along certain crystallographic orientation of the matrix. The fine precipitates distributed rather uniformly throughout the matrix are $\gamma^{\prime}$ particles. Note the $\gamma^{\prime}$-free zone formed around $\eta$ precipitates. Figures 6(a) and (b) show a bright-field image and diffraction pattern of a sample solution treated at $1075^{\circ} \mathrm{C}$ for $1 \mathrm{hr}$ and aged at $800^{\circ} \mathrm{C}$ for $25 \mathrm{hrs}$. These results clearly show the presence of $\gamma^{\prime}$ precipitates finely distributed within the FCC matrix. 
Table I. Hardness results of samples solution treated at $1050^{\circ} \mathrm{C}$

\begin{tabular}{|c|c|c|c|}
\hline $\begin{array}{c}\text { Aging Temp. } \\
\text { Aging time(hr) }\end{array}$ & $700^{\circ} \mathrm{C}$ & $750^{\circ} \mathrm{C}$ & $800^{\circ} \mathrm{C}$ \\
\hline As solutioned & 254 & 254 & 254 \\
\hline 1 & 372 & 388.7 & 399 \\
\hline 2 & 375.3 & 402.7 & 425.3 \\
\hline 4 & 392.3 & 429 & 425.33 \\
\hline 8 & 392.3 & 433 & 445.3 \\
\hline 25 & 399 & 445.7 & 454 \\
\hline
\end{tabular}

Table II. Hardness results of samples solution treated at $1075^{\circ} \mathrm{C}$

\begin{tabular}{|c|c|c|c|}
\hline Aging time(hr) & $700^{\circ} \mathrm{C}$ & $750^{\circ} \mathrm{C}$ & $800^{\circ} \mathrm{C}$ \\
\hline As Solutioned & 198 & 198 & 198 \\
\hline 1 & 234 & 298.7 & 301 \\
\hline 2 & 261 & 325.7 & 348 \\
\hline 4 & 277 & 333.7 & 388.7 \\
\hline 8 & 298.7 & 351 & 399 \\
\hline 25 & 336.3 & 378.3 & 413.7 \\
\hline
\end{tabular}

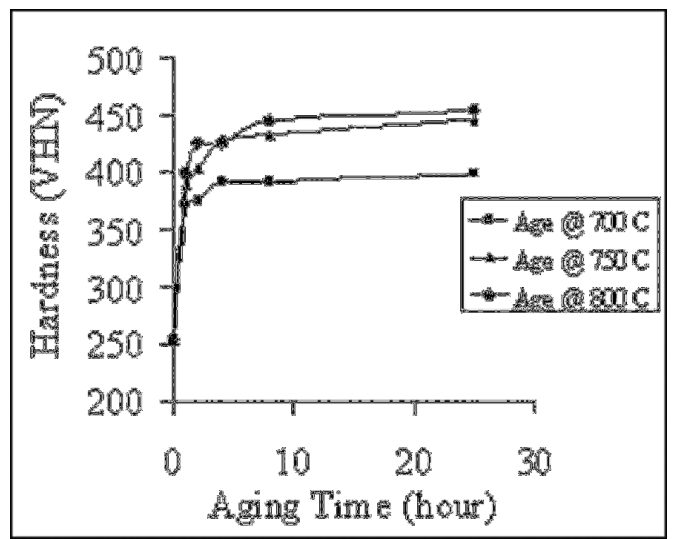

Figure 1. Influence of aging time and temperature on hardness of samples solution treated at $1050^{\circ} \mathrm{C}$.

No sign of $\eta$ particles was found in this sample. The four parallel features are stacking faults which are typically formed due to removal of $\mathrm{Ni}$ in areas where large volume fraction of $\gamma^{\prime}$ is formed. Note the smaller size of $\gamma^{\prime}$ precipitates in this sample compared to those found in the sample solution treated at $1050^{\circ} \mathrm{C}$. The average size of $\gamma^{\prime}$ precipitates corresponding to Figures 5 and 6 were measured to be 13.2 and $8.6 \mathrm{~nm}$, respectively.

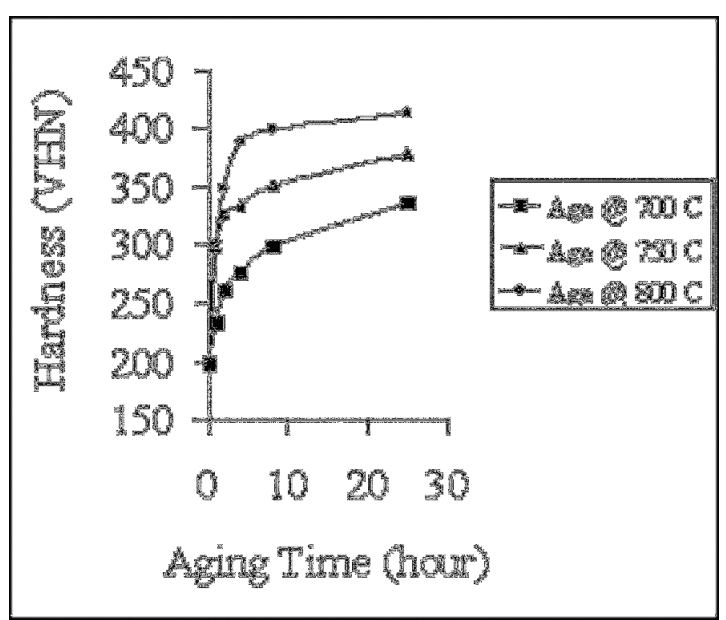

Figure 2. Influence of aging time and temperature on hardness of samples solution treated at $1075^{\circ} \mathrm{C}$.

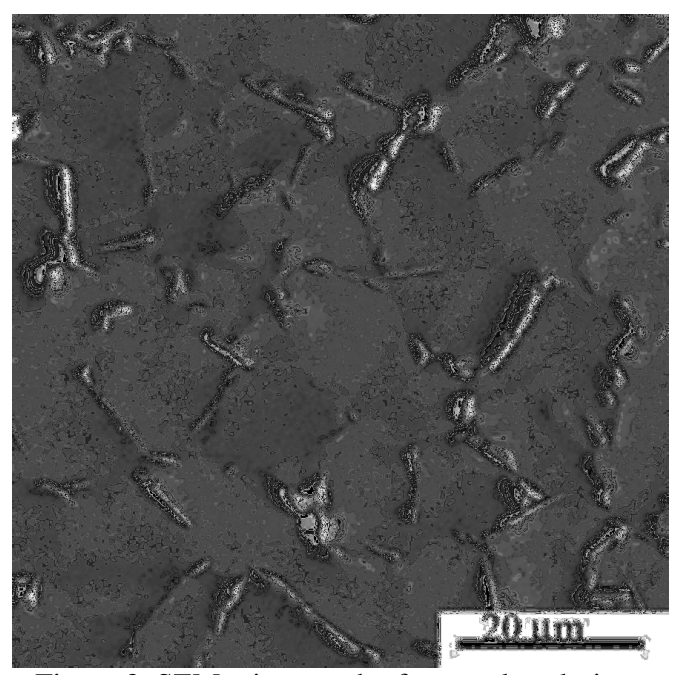

Figure 3. SEM micrograph of a sample solution treated at $1050^{\circ} \mathrm{C}$ for $1 \mathrm{~h}$.

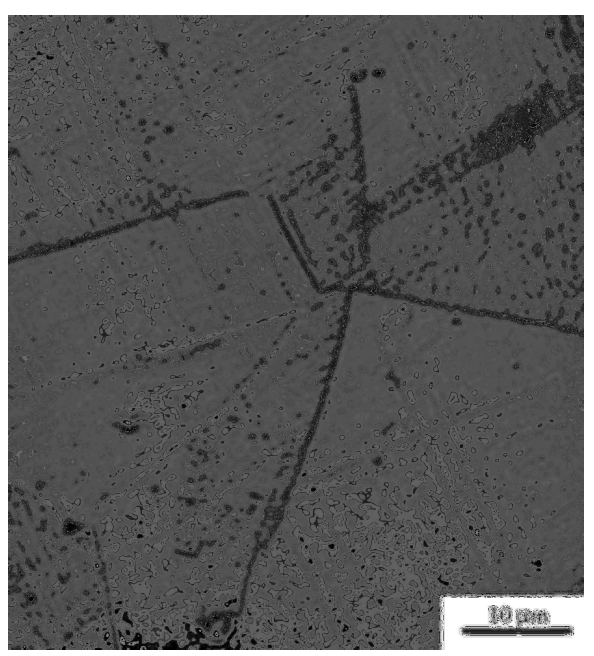

Figure 4. SEM micrograph of a sample solution treated at $1075^{\circ} \mathrm{C}$ for $1 \mathrm{hr}$. 
Figures 7 and 8 show the results of $\eta$ lengthening and thickening measurements during aging of the alloy. It is apparent that $\eta$ precipitates are elongated while the thickness of these precipitates does not change during aging. The coherent interface hinders thickening of $\eta$ precipitates during aging since individual atomic transfer across the coherent interface is usually not favorable due to increase in energy $[9,10]$.

Results of this study reveal different aspects of precipitation behavior of AEREX 350.

Hardness results show that for the same aging treatment, hardness of samples solution treated at $1050^{\circ} \mathrm{C}$ are generally higher than hardness of samples solution treated at $1075^{\circ} \mathrm{C}$. Microstructural investigations showed that presence of $\eta$ precipitates in the microstructure of samples solution treated at $1050^{\circ} \mathrm{C}$ results in increased hardness of these samples. The initial sharp increase in the hardness of the samples solution treated at $1050^{\circ} \mathrm{C}$ may be attributed to the local increase in the $\gamma^{\prime}$ forming elements in the supersaturated solid solution due to formation of $\eta$ during the solution treatment. It has been reported that increasing the supersaturation by increasing the $\gamma^{\prime}$ forming elements enhances the rate of $\gamma^{\prime}$ growth [8]. At long aging times (more than $4 \mathrm{~h}$ ) the rate of hardening is significantly diminished compared with that observed at shorter aging times. This may be related to the fact that at long aging times $\gamma^{\prime}$ coarsening and $\eta$ lengthening occur simultaneously. In addition, $\eta$ lengthening occurs at the expense of $\gamma^{\prime}$ particles. On the other hand, $\gamma^{\prime}$ precipitates dissolve in matrix and the solute atoms diffuse to incoherent tip of $\eta$ precipitates results in lengthening of $\eta$ precipitates. It is also consistent with the $\eta$ lengthening results. The combination of these mechanisms may lead to a steady but small increase in hardness, as seen in Figure 1.

Grain size measurements showed that increasing the solution treatment temperature by $25^{\circ} \mathrm{C}$ results in grain growth from ASTM 8 to ASTM 7. This may be justified by the absence of $\eta$ phase in samples solution treated at $1075^{\circ} \mathrm{C}$. Under this situation, grain boundary migration occurs more freely leading to an increase in final grain size of the material. As seen in Figure 5, presence of $\eta$ at grain boundaries hinders movement of grain boundaries. The origin of this resistance is believed to be due to the coherency of the $\eta$-matrix interface.

Based on microstructural results obtained in this investigation, it is proposed that different solution treatment temperature may be used for different applications of AEREX 350. Solution treatment of the thermomechanically processed alloy below the $\eta$ solvus temperature improves the strength of the alloy while solution treatment at temperatures above the $\eta$ solvus temperature improves stress rupture properties of the alloy.

\section{Conclusion}

Hardness results showed that the hardness of samples solution treated at $1050^{\circ} \mathrm{C}$ was generally higher than the hardness of samples solution treated at $1075^{\circ} \mathrm{C}$. The hardness of samples solution treated at $1050^{\circ} \mathrm{C}$ showed a sharp increase for aging times up to $4 \mathrm{~h}$, followed by a steady but small increase for longer aging times, while the hardness of samples solution treated at $1075^{\circ} \mathrm{C}$ increased steadily with increasing aging time.

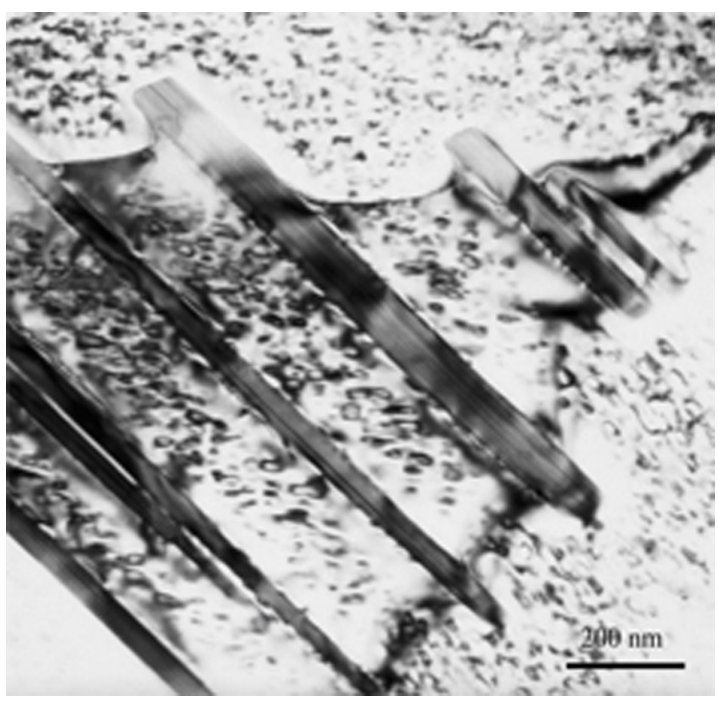

Figure 5. Bright-field TEM image of a sample solution treated at $1050^{\circ} \mathrm{C}$ for $1 \mathrm{hr}$ and aged at $800^{\circ} \mathrm{C}$ for $25 \mathrm{~h}$.

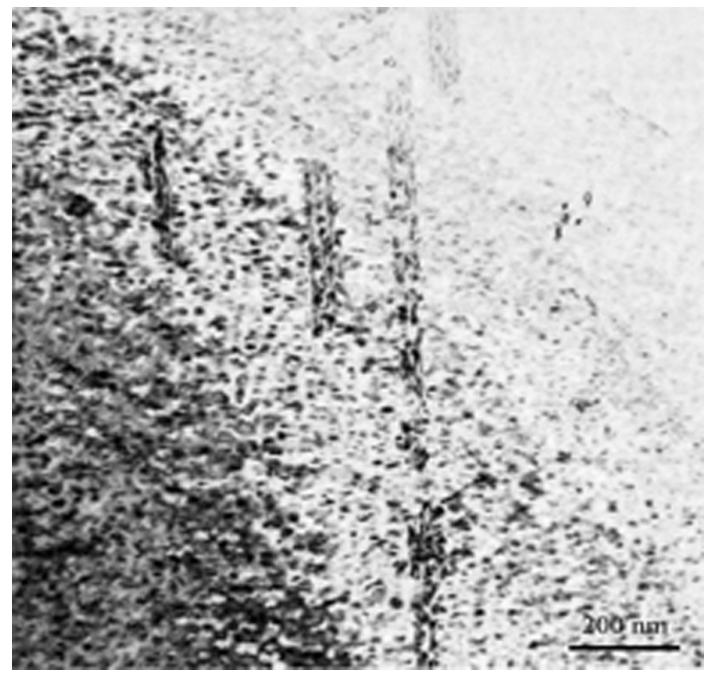

a)

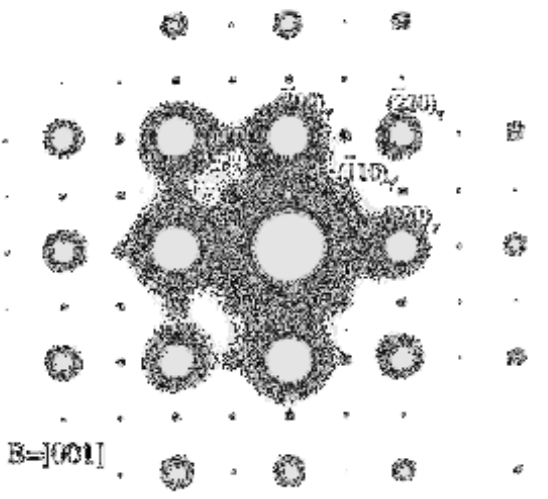

b)

Figure 6. TEM micrograph of a sample solution treated at $1075^{\circ} \mathrm{C}$ for $1 \mathrm{~h}$ and aged at $800^{\circ} \mathrm{C}$ for $25 \mathrm{~h}$ : (a) Bright-field image (b) diffraction pattern 


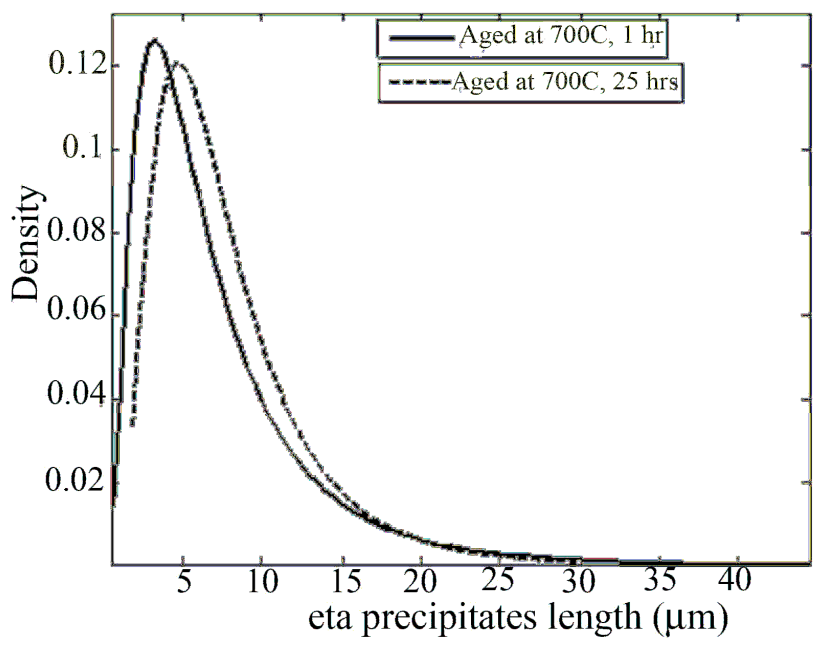

Figure 7. Distribution of the length of $\eta$ precipitates for two samples solution treated at $1050^{\circ} \mathrm{C}$ and aged at $700^{\circ} \mathrm{C}$ for 1 and $25 \mathrm{~h}$.

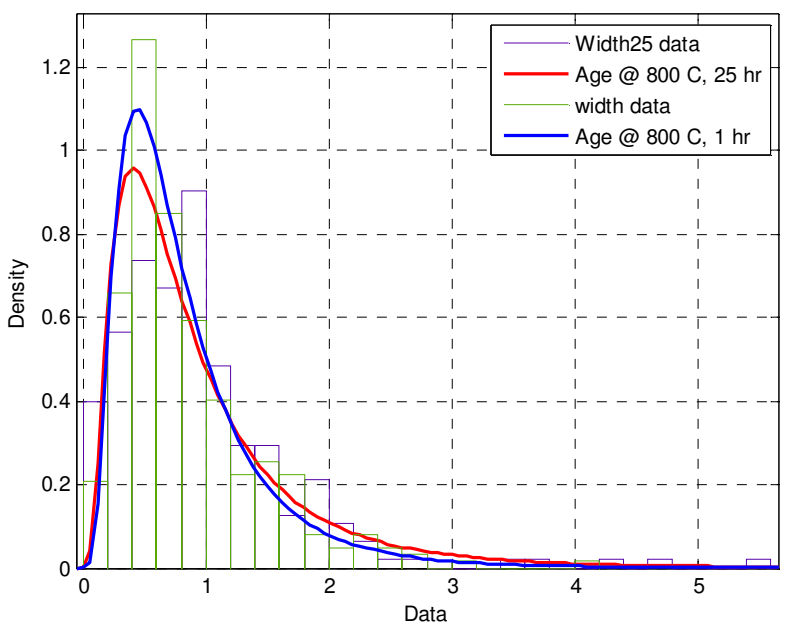

Figure 8. Distribution of the thickness of $\eta$ precipitates for two samples solution treated at $1050^{\circ} \mathrm{C}$ and aged at $800^{\circ} \mathrm{C}$ for 1 and $25 \mathrm{~h}$.

Image analysis investigations on samples solution treated at $1050^{\circ} \mathrm{C}$ showed that $\eta$ lengthening occurs during aging of these samples while thickness of these precipitates showed no changes during aging of these samples.

Microstructural studies showed that the size of $\gamma^{\prime}$ precipitates was larger in samples solution treated at $1050^{\circ} \mathrm{C}$ compared to that solution treated at $1075^{\circ} \mathrm{C}$. This may be attributed to larger supersaturation in samples solution treated at $1050^{\circ} \mathrm{C}$. This may also justify the sharp increase in hardness of samples solution treated at $1050^{\circ} \mathrm{C}$ at short aging times.

At long aging times, the combination of $\gamma^{\prime}$ coarsening, thermodynamic instability of $\gamma^{\prime}$ with respect to $\eta$ phase and lengthening of $\eta$ precipitates leads to steady but small increase in hardness of samples solution treated at $1050^{\circ} \mathrm{C}$.
Solution treatment of $\mathrm{AEREX}^{\mathrm{TM}_{3}} 30$ at $1050^{\circ} \mathrm{C}$ results in precipitation of $\eta$ phase at grain boundaries which may be used to control grain size at the expense of stress rupture life. Solution treatment at $1075^{\circ} \mathrm{C}$ results in $\eta$-free processing which leads to increased stress rupture life.

Precipitation of $\eta$ phase during solution treatment causes formation of serrated grain boundaries. This is attributed to the semicoherent interface formed between $\eta$ and the surrounding matrix.

\section{Acknowledgement}

The authors acknowledge Sharif University of Technology for providing financial support for this study and Ms. Amini of electron microscopy lab. for preparing TEM samples.

\section{References}

[1] S. Asgari, E. El-Danaf, S.R. Kalidindi, R.D. Doherty, "Strain Hardening Regimes and Microstructural Evolution During Large Strain Compression of Low Stacking Fault Energy FCC Alloys that Form Deformation Twinning" Metall. Mater. Trans., 28A (1997), 1781-1795.

[2] S. Asgari, E. El-Danaf, E. Shaji, S.R. Kalidindi, R.D. Doherty, "The Secondary Hardening Phenomenon in Strain-hardened MP35N Alloy" Acta Mater. 46 (1998), 5795-5806.

[3] C.M. Tomasello, F.S. Pettit, N. Birks, J.L. Maloney, J.F. Radavich, "Precipitation Behavior in AEREX350" (Paper presented at the Eighth International Symposium on Superalloys, Champion, Pennsylvania, 22 September 1996 ), 145.

[4] S. Asgari, "Age-hardening Behavior and Phase Identification in Solution-treated AEREX 350 Superalloy" Metall. Mater. Trans. 37A (2006), 2051-2057.

[5] M. Samiee, S. Asgari, "Influence of Solution Treatment on Precipitation Behavior of a Ni-Co Alloy" Scripta Materialia 57 (2007), 93-96.

[6] E. W. Ross, C. T. Sims, in: C. T. Sims, W. C. Hagel (Eds.), Superalloys II, Wiley, New York, NY, 1986, PP. 97-133.

[7] M. Farvizi, S. Asgari, "Effects of Cold Work Prior to Aging on Microstructure of AEREX350 Superalloy" Mater. Sci. Eng. A, 480 (1) (2007), 434-438.

[8] B.R. Clark, F.B. Pickering, "Precipitation Effects in Austenitic Stainless Steels. Containing Titanium and Aluminium additions" JISI 205 (1967) 70-84.

[9] J. M. Howe, H. I. Aaronson, R. Gronsky, "Atomic Mechanisms of Precipitate Plate Growth in the Al-Ag System- I. Conventional Transmission Electron Microscopy" Acta Metall. 33 (1985), 639-648.

[10] J. M. Howe, H. I. Aaronson, R. Gronsky, "Atomic Mechanisms of Precipitate Plate Growth in the Al-Ag SystemII.High-resolution Transmission Electron Microscopy" Acta Metall. 33 (1985), 649-658. 